Revista de Comunicación de la SEECI. (Noviembre 2014). Año XVII (35),

106-127 ISSN: 1576-3420

http://dx.doi.org/10.15198/seeci.2014.35.106-127

INVESTIGACIÓN/RESEARCH

Recibido: 24/04/2014-----Aceptado: 19/05/2014-----Publicado: 15/11/2014

\title{
IMPACTO DE LAS TIC Y EL 2.0: CONSECUENCIAS PARA EL SECTOR DE LA COMUNICACIÓN
}

David Caldevilla Domínguez: Universidad Complutense. España.

davidcaldevilla@ccinf.ucm.es

\section{RESUMEN:}

La implantación de las diversas Redes sociales ha cambiado radicalmente la percepción de las relaciones sociales y la forma en la que invertimos nuestro tiempo libre (Caldevilla, 2010). Estudios actuales indican que esta tendencia es irreversible y que, además estas Redes socializantes son herramienta de búsqueda de trabajo (Linkedin, Xing, Viadeo), mantener la relación con los amigos, e incluso ejercer el periodismo a nivel de calle (Campos Freire, 2008).

También repasaremos trabajos que advierten de nuevos riesgos (Bautista Sancho, 2013): de entre los que destacan la pérdida de privacidad, la adicción a la conexión, la pérdida de productividad laboral, el intrusismo...

Nuestra hipótesis versa sobre los efectos de lo 2.0 en la nueva fórmula comunicativa de principios del siglo XXI, que abole la anterior por sobreposición.

PALABRAS-CLAVE: Facebook - Tuenti - Redes sociales - Internet - 2.0 - Ocio electrónico - TIC.

\section{IMPACT OF CIT AND 2.0: CONSEQUENCES FOR THE COMMUNICATIONS SECTOR}

\section{ABSTRACT:}

The 'social network phenomenon' has radically changed our perception of social relationships, and the way we invest our free time (Caldevilla, 2010). Recent studies show this tendency will not stop, and also that those socializer networks are a tool in vital areas such as job-search (Linkedin, Xing, Viadeo), keep relationship with friends and even practice journalism at a Street level (Campos Freire, 2008).

We'll also see documents that warn about new risks (Bautista Sancho, 2013, p. 11): being the most important the loose of privacy, internet addiction, lose of productivity, professional infiltration... 
Our Hypothesis focuses the effects of 2.0 in the new communications formula of the XXI century, that abolish the former one by over-exposure.

KEY WORDS: Facebook - Tuenti - Social Networks - Internet - 2.0 - eentertainment- ICT.

\section{INTRODUCCIÓN}

Las Redes sociales generan interconexiones promovidas por los propios usuarios: la participación del usuario supone, en sí misma, su definición como 2.0 frente a lo 1.0 o relación unidireccional de las web anteriores (Bautista Sancho, 2013) ${ }^{1}$.

El resultado final se centra en la existencia de nuevos escenarios sociales y las consecuencias o influencias que pueden tener en la realidad. Como apunta Manuel Castells $^{2}$, el resultado final se resume en que "La gente se está montando sus propios sistemas de información y de comunicación y en ese proceso se van generando nuevas formas de relación mediática y nuevas oportunidades empresariales" (2008, p. 2).

Este estudio parte de la hipótesis de que estos nuevos y extendidos medios pueden absorber la atención del público hasta el punto de suponer un menoscabo para las audiencias de los medios tradicionales, pues permiten un nivel de información inmediato y alto, con una interactividad sin competencia, y una libertad editorial casi indudable. Este nuevo paradigma informativo va a suponer un nuevo modelo de negocio que suponga una radical transformación de las estructuras laborales y técnicas de lo comunicativo (prensa, radio, audiovisual, literatura...).

\section{OBJETIVOS}

Partimos de un axioma: Las grandes protagonistas actuales de la sociedad digital son las Redes sociales. Nadie cuestiona ya el imparable poder que están adquiriendo; de forma aún más significativa si cabe a partir de la implantación generalizada de la "Cultura de la portabilidad" (Kischinevsky, 2009).

\section{METODOLOGÍA}

Analizaremos los datos de difusión de las principales redes sociales en los últimos años, y los compararemos con los de consumo de los medios convencionales.

\footnotetext{
${ }^{1}$ Bautista Sancho, L. (2013). Relatos 2.0: las autobiografías en la Web social; en Redes sociales y 10 2.0 y 3.0. Visión Libros: Madrid.

2 Castells, M. (2008). La autocomunicación de Masas. Disponible en: www.renata.edu.co/index.php/component/content/article/5-noticias/191-ieres-un-autista-digital-pormanuel-castells-.html. Consultado el 20 de agosto de 2014.

${ }^{3}$ Kischinevsky, M. (2009). Cultura da portabilidade. Novos usos do rádio e sociabilidades em mídia Sonora, en OBS Journal, no 8, p. 223-238.
} 
Buscaremos las posibles correlaciones entre ambos y utilizaremos los estudios previos para alumbrar el camino de lo que será el futuro modelo mixto de comunicación (Si bien se prevé que cese la fundación de nuevos diarios de papel, no lo está a tan corto plazo la desaparición, al menos, de las cabeceras importantes).

\section{RESULTADOS}

La mayoría de los usuarios activos de Internet y las Redes sociales son jóvenes: sólo en España, entre los 16 y los 24 años se eleva al $95,5 \%$ y entre los 25 y 35 alcanza un $87 \%$ (ONTSI, 2013).

En referencia a estos usuarios actores y receptores, a un mismo tiempo, de las TIC y del fenómeno MEDIA se ha estudiado el desarrollo de la Sociedad de la Información, lo que ha dado lugar a un entorno omnipresente en el que se insertan e interactúan los sujetos por vez primera en la historia de manera nodal no concéntrica (Alonso Mosquera y Muñoz de Luna, 2014). Fruto de este contexto, las nuevas generaciones de jóvenes piensan y procesan la información de un modo completamente diferente respecto a sus predecesores (Prensky, 2001, p. 1). ${ }^{5}$

Para explicar este fenómeno hemos de referenciarnos a la definición aportada en las Jornadas sobre Gestión en Organizaciones del Tercer Sector en la Universidad Di Tella de Buenos Aires, Argentina, en noviembre de 2001, que aún hoy sigue estando en vigor con pequeñas matizaciones que más tarde apuntaremos.

"Las Redes son formas de interacción social, definida como un intercambio dinámico entre personas, grupos e instituciones en contextos de complejidad. Un sistema abierto y en construcción permanente que involucra a conjuntos que se identifican en las mismas necesidades y problemáticas y que se organizan para potenciar sus recursos.

Una sociedad fragmentada en minorías aisladas, discriminadas, que ha desvitalizado sus redes vinculares, con ciudadanos carentes de protagonismo en procesos transformadores, se condena a una democracia restringida. La intervención en red es un intento reflexivo y organizador de esas interacciones e intercambios, donde el sujeto se funda a sí mismo diferenciándose de otros." (Conclusiones de las jornadas sobre Gestión en Organizaciones del Tercer Sector citadas por Alemañy ${ }^{6}$ ).

De lo que se infiere que para esta corriente de pensamiento, las Redes sociales nacen como una reunión de personas, conocidas o desconocidas, que interactuarán entre sí, redefiniendo al grupo y retroalimentándolo. Esta idea enlaza con la cultura de la web 2.0 que no es un nuevo modismo para superar por elevación lo que antes definíamos como "hacer algo en grupo" y que ahora rompe la propia estructura

4 ONTSI (2013). Informe anual la Sociedad en red 2012. Disponible en www.ontsi.red.es/ontsi/es/estudios-informes. Consultado el 29 de agosto de 2014.

${ }_{5}^{5}$ Prensky, M. (2001). Digital Natives, digital inmigrants, en On the Horizont, vol.9 no 55. Disponible en: www.emeraldinsight.com/journals.htm?articleid=1532742 Consultado el 29-08-2014.

${ }^{6}$ Alemañy Martínez, C. (2009). Redes sociales: una nueva vía para el aprendizaje, en Cuadernos de Educación y Desarrollo, no 1, vol. 1. Disponible en: www.eumed.net/rev/ced/01/cam4.htm. Consultado el 30 de agosto de 2014. 
rígida de 'grupo' (Sorokin, 1947) para ser entendidos sus miembros como piezas de un mecano, capaces de moldear cualquier tipo de figura que imaginemos y de combinarse y descombinarse con otros mecanos de manera casi instantánea. La gran ventaja que supone el trabajo grupal es que prospera por el esfuerzo de todos los intervinientes en ámbitos como el educativo. Siguiendo el trabajo de Túñez y Sixto (2012, p. 78-79) convenimos con ellos que "La web 2.0 no consiste en un cambio tecnológico aislado, sino en un modelo que concibe el aprendizaje como el resultado de la interacción y la colaboración de las personas y que sitúa al estudiante en el centro del proceso, por lo que ha de entenderse como un instrumento facilitador de los procesos de aprendizaje".

Así, las Redes sociales crecen con lo que añade cada usuario, de manera no unidireccional sino que, pese a que un elemento guíe o dirija, comenzando a esbozar un planteamiento o idea, es el conjunto de los internautas con sus respuestas, referencias, opiniones y desacuerdos el que hace que la página, y por ende el flujo de la comunicación, funcione y crezca (Tabernero et al., 2010; Alonso Mosquera y Muñoz de Luna, 2014). Este valor numérico cuantifica también el poder de la información en él contenida y su valor monetario para publicistas (Castelló, 2010).

\subsection{La web 2.0 y el mundo 2.0}

Empleado como indicativo respecto a la web primigenia, o 1.0, el hoy celebérrimo nombre de 'web $2.0^{\prime}$ se debe al autor Tim O'Reilly (2004) en una conferencia destinada a diseccionar el aún novedoso fenómeno.

La web -y la bitácora- 2.0 constituye un espacio de Internet que concede una importancia preferente a lo social. A través, por ejemplo, de la revalorización personal o de la interacción de los individuos que los visitan y comentan, colaborando para promover una transformación total de la forma primitiva de comprender el periodismo o la comunicación (Caldevilla y Visa Barbosa, 2013).

¿Se podría hablar, por ello, de "profesionales 2.0"?. Todo internauta que aprovecha activa y extensivamente los avances tecnológicos de última generación para mejorar su eficacia en el trabajo puede ser susceptible de tal definición; incluso hablar de "empresas 2.0", quienes, según la definición más universalmente aceptada "son aquellas que, por analogía con la web 2.0, toman la referencia de ésta en lo que se refiere al uso de herramientas de informática social (...) No sólo el simple uso de estas herramientas sino también cambios más profundos relacionados con la identidad de las personas y las relaciones entre ellas, cabe considerar a la empresa 2.0 como una herramienta más para gestión de negocios. Así pues, englobaría el uso de los principios y prácticas de la denominada web social como plataforma de actuación" (Mc Afee, 2008, p. 23). Por elevación conceptual, el apelativo llega a otros términos como "Universidades 2.0" que son un 'concepto emergente de Universidad' con una finalidad más social, en la que la comunidad universitaria 7 O'Reilly, T. (2004). "What is web 2.0". Conferencia disponible en:
http://oreilly.com/web2/archive/what-is-web-20.html. Consultado el 30 de agosto de 2014. 
muestra su faz colaborativa de forma abierta a través de uso de las nuevas herramientas y aplicaciones, mucho más fluidas, generando, así, un espacio de comunicación eficaz entre profesores, alumnado, sociedad, administración, etc... (Piñeiro-Otero y Caldevilla, 2011)

\subsubsection{Historia de las Redes sociales en el mundo}

Isabel Ponce $(2012)^{8}$ afirma que la historia reciente de las Aplicaciones sociales puede establecerse a partir de la crisis informática del año 2003, cuando casi todas las empresas que habían nacido y crecido, al albur de los mercados financieros, se declaraban en quiebra y cerraban sus portales de Internet por la falta de visitas y de precipitación de los economistas en el benigno análisis del nuevo modelo de negocio (autores como Mandel o Piscilettly). Inspirándose en la mensajería instantánea y en la proliferación de los foros de discusión, tres norteamericanos crearon en ese momento, sendas empresas destinadas a que los internautas pudieran 'hablar' entre ellos. Los tres estaban relacionados entre sí a través de una compañía, Friendster en la que todos intervinieron. Se trata de Marc Pincus, Reid Hoffman y Jonathan Abrams, quienes ponen en marcha respectivamente Tribe.net, Linkendin y la ya mencionada Friendster, las tres primeras Redes sociales de Internet, lo que supondría un giro sólo comparable al copernicano en la historia de la Humanidad.

Al comenzar en 2003 la recuperación de la economía digital -con nuevos paradigmas mercantiles-, estas tres empresas gestoras de Redes sociales empiezan a incrementar su número de usuarios. Friendster, se haría famosa ese mismo año a raíz de las elecciones primarias en Estados Unidos, ya que el candidato Howard Dean la empleó profusamente en su campaña. El tráfico se incrementó tan exponencialmente que se superó la capacidad de los servidores. Algo inaudito hasta la fecha en una Red social.

8 Ponce, I. (2012). Historia de las Redes sociales. Disponible en http://recursostic.educacion.es/observatorio/web/ca/internet/web-20/1043-redes-sociales?start=2. Consultado el 20 de agosto de 2014. 


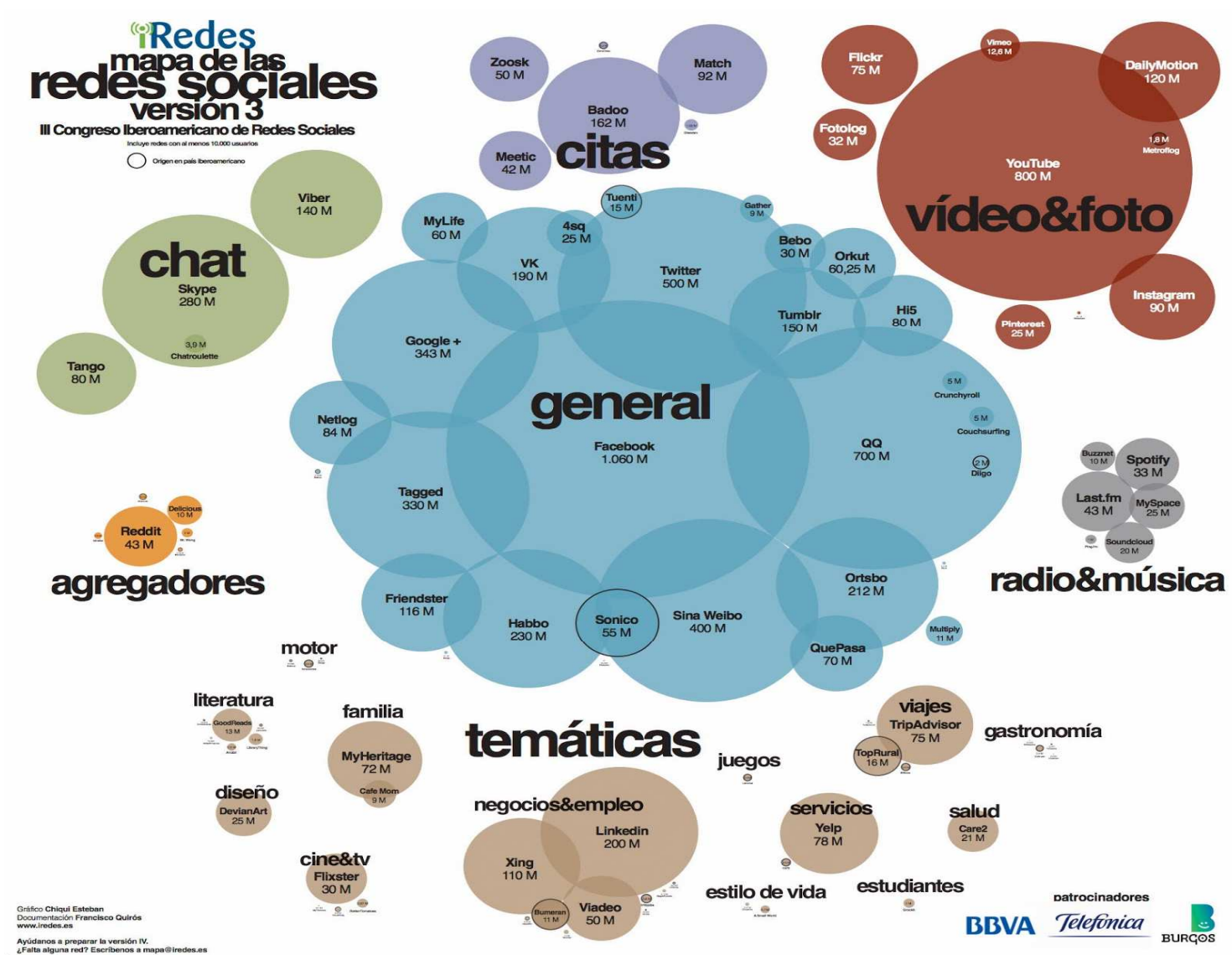

Imagen 1: Tipología de las Redes sociales actuales y nube gráfica de su clasificación.

Fuente: iRedes 2013

Según el grafico obtenido de iRedes $2013^{9}$, del tipo burbujas proporcionales, lo cual sinópticamente sirve para resaltar la importancia de cada elemento en relación a los demás, en el centro hallamos las Redes más generalistas y en los extremos las que van a ciertos nichos formalmente especializados: por temas (para aficionados), por estados vitales (como por ejemplo, por edades), las de uso profesional (y activista) y las que están centradas en el contenido que intercambian sus usuarios.

\subsection{Dos aspectos básicos: Usos principales de las Redes sociales y palabras clave para su comprensión:}

Usos principales de las Redes sociales

Holísticamente, los estudios especializados (Ponce, 2012) hallan cuatro actividades/necesidades principales que motivan al uso de las Redes sociales. Son varios los perfiles de los usuarios en función del nivel cultural, sociológico,

\footnotetext{
${ }^{9}$ IREDES (2013). Mapa de las Redes sociales. Disponible en www.iredes.es/2013/03/tercera-versiondel-mapa-iredes/. Consultado el 28 de julio de 2014.
} 
geográfico, etc... Sin embargo, cualquier usuario es clasificable como necesitado de interactuar con otra gran masa de internautas a los que se quiere sentir psicológicamente unido.

De acuerdo con Del Moral $(2005)^{10}$ estas cuatro necesidades son:

- Mantener las amistades

- Creación de nuevas amistades

- Ocio y Entretenimiento

- Gestión interna de organizaciones empresariales

\section{Palabras clave para la comprensión de las Redes sociales}

\subsubsection{Interactividad}

"Una expresión extensiva que en una serie de intercambios comunicacionales implica que el último mensaje se relaciona con mensajes anteriores a su vez relativos a otros previos" (Rafaeli, 1988) Las nuevas tecnologías hacen posible la aplicación global de esta definición. A distancias ilimitadas podemos enviar formas textuales de longitud limitada a través del móvil (sms) o ilimitada con vídeo e imágenes (Whatsapp), podemos sacar fotografías de gran calidad con el mismo terminal y enviarlas a la otra punta del mundo, emitir en directo y redirigir la señal de televisión vía satélite, e incluso hacer que esas mismas imágenes, mientras se reproducen en el televisor se copien a un disco duro y 'se suban' a un servidor de Internet para ofrecerse en diferido por streaming... Esta 'macrored' a nivel mundial, reduce drásticamente los costes de producción de la información y las piezas audio-visuales, posibilitando, así, la difusión digital y facilitando la analógica (Gómez-Escalonilla, 2007).

La instantaneidad (Rafaeli) es el gran avance que cubre este campo, lo que condenará a las empresas de mensajería y correos a ocupar un sector residual de mercado, así como a la prensa escrita a reinventarse -el último periódico impreso en España, se calcula que saldrá en 2024- (Dawson, 2006). El Modelo de negocio está cambiando para mal y para bien, como señala Martínez Molina (2010): De manera que si la red le ha quitado lectores a las versiones impresas de los diarios, también les ha dado un número muy superior de visitantes a sus sitios. The New York Times, con una difusión de lunes a sábado de cerca de un millón de ejemplares, tiene 22 millones de usuarios únicos por mes en la internet dentro de los Estados Unidos. The Guardian vende unas 300.000 copias por día en el Reino Unido pero su edición electrónica es vista por cerca de 36 millones de personas en todo el mundo: 120 veces más. The Times de Londres tiene 673.000 compradores por día y 21 millones de visitantes por mes.

Esa accesibilidad lleva a que un tráfico multitudinario de personas puedan interactuar en páginas web, bitácoras, foros, chat, Redes sociales, conferencias a distancia, etc.:

\footnotetext{
${ }^{10}$ Del Moral, J. A. (2005). Redes sociales ¿Moda o nuevo paradigma?. Madrid: Asociación de usuarios de Internet.
} 
las piezas podrían estar en manos del público en un tiempo ínfimo, posibilitando actualizaciones más periódicas y seguimientos más precisos.

Lo que nació de la necesidad humana de compartir un pensamiento por parte de un usuario (Caldevilla, 2009), habrá sido leído por cientos de miles o millones de personas en la Red sólo un lapso de tiempo más tarde. Otro usuario ha podido querer compartir su opinión al respecto y, a su vez, ha escrito sobre el primer texto en su Twitter o en su Tuenti (o en cualquier otra Red social), y, tras esto, otra infinidad de jóvenes podrá interactuar y completar la información generando un debate en pocos minutos, obteniendo comentarios y respuestas a sus ideas casi de forma inmediata.

El riesgo de informar y ser informado erróneamente y dar lugar a equívocos, engaños o generar desinformación interesada es ya un mal endémico en la Red, cada vez más carente de profesionales que velen por ser los guardabarreras erigiéndose como última línea de defensa del mundo libre (Doval y Martínez Rodríguez, 2012).

De esta interactividad propia del medio proviene la ventaja (o desventaja) de poder generar cambios de conducta a través de campañas de mercadeo viral, que hallan en Internet un vehículo impensable hace sólo unos años. Pero no sólo eso, gracias a Internet y las Redes sociales se puede modificar una conducta, crear nuevos movimientos de opinión, partidos políticos, plataformas reivindicativas, promover manifestaciones, crear grupos de apoyo a causas concretas o conseguir crear una moda que genere el consumo de un determinado producto. La ley está cercenando cada vez más este tráfico de información cuando su fin atenta contra los intereses del partido en el Gobierno.

La relación entre usuarios de plataformas como las Redes sociales pasa de ser vertical a horizontal, posibilitando una igualdad figurada, propiciatoria de que cualquier internauta se convierta en emisor, produciendo sus propios contenidos, y transmisor/receptor de información. Tal llega a ser su número que los teóricos de las Redes ya han acuñado el término Infoxicación (Caldevilla, 2013).

Ante este volumen de espectadores ( $\mathrm{y}$ ahora también autores) las empresas de publicidad no pueden quedar al margen. Nos encontramos a efectos prácticos, con la publicidad y la propaganda 2.0, como nuevo modelo de negocio basado en el mayor consumo de pantalla de ordenador que de la de televisión (Martínez Molina, 2006). Incluso se especula desde hace años con la llamada 'pantalla única', hoy ya posible con las televisiones conectadas a Internet y a los dispositivos móviles personales (tabletas, móviles, discos duros y lápices de memoria...)

\subsubsection{Personalización}

"Por customización (personalización) se entiende que el cliente puede escoger la opción que más le interesa entre una serie de posibilidades (...) Por otro lado, va a ser cada vez más difícil dar servicios realmente personalizados, entendiendo por ello que el cliente es quien define las características del producto o servicio." (Cornellá, 2000, p. 1) 
Las Redes sociales permiten tener al usuario un mayor control sobre qué noticias desea recibir, destacar y compartir. Se pueden crear portadas personalizadas de medios en línea, según preferencias, creando un producto original, único y acorde al propio gusto.

A partir de este propósito de personalización, se filtra el correo electrónico evitando que nos lleguen correos basura o no deseados, e incluso se pueden recibir en el correo electrónico las noticias y artículos que interesan más a través de las RSS (sistemas de redifusión de noticias a través de Internet a las que el usuario se puede suscribir).

Las Redes sociales refuerzan la confianza y seguridad en uno mismo en la interrelación, puesto que podemos determinar con quién, cómo y cuándo comenzaremos una conversación, y por supuesto, cuándo está se acabará de forma natural o a través de "el veto de usuarios", y otras herramientas similares propias sólo de Internet. De esta forma en pocos días podemos conseguir que nuestro perfil tenga cientos de amigos, lo que repercute positivamente en nuestra autoestima. Actualmente existen empresas que venden por módicos precios 'seguidores' en twitter o visitantes de web para que los buscadores desvirtúen los resultados de sus algoritmos y promocionen empresas o personas por encima del interés real suscitado (Caldevilla, 2013).

Por último, las Redes sociales son un buen medio para compartir parte de la experiencia vital que nos hace individuales. Paradójicamente, el hombre de este siglo es el más estudiado, encuadrado, previsible y controlado de toda la historia, quizá por ello necesita personalizar lo que le rodea, todo lo posible, por razones de identidad, extremo que se ve reforzado por los mensajes de la publicidad y negado por la tecnología al servicio de los Gobiernos, empresas y piratas informáticos. Por eso se construyen avatares y perfiles ad hoc (para amigos, para familiares, en el trabajo...), se modifican los iconos de los sistemas operativos, se varían los botones y la apariencia de los navegadores o simplemente se redactan bitácoras cuyo fin es compartir pensamientos, imágenes y opiniones mientras se busca la reafirmación de la propia identidad.

Todo este intercambio comunicativo permite contactar con gente a la que sería imposible acceder de otra forma, dada su lejanía física y temporal. Se crea una relación virtual con cierto carácter de familiaridad (O'Reilly, 2004; Rodríguez Andrés y Ureña Uceda, 2012). Los grupos se afianzan mediante quedadas y chat así como mediante foros restringidos. Se pueden compartir opiniones, aficiones, imágenes, vivencias, anhelos, miedos, ideologías y emociones a través de plataformas como Facebook, Hi5, Tuenti o Xing.

El amor halla también lugar, pues de las míticas discotecas de hace unos años o de las relaciones salidas del trabajo, se está pasando a una moda creciente basada en otro modelo de Redes: las de relaciones o búsqueda de pareja como Meetic o eDarling, que a su vez atraen a distintos tipos de personas con una necesidad común: edades comprendidas entre los 35-40, nivel cultural medio-alto; más mujeres en Meetic y una proporción marginalmente menor en su competidora (Álvarez, 2014). 
A efectos del sector de la comunicación, son muchas las iniciativas distintas para aprovechar esta nueva funcionalidad/demanda de los usuarios:

"Hace unos años, medios internacionales como el diario británico The Guardian apostaron por implementar una herramienta en sus versiones digitales que sugería una serie de noticias aleatorias al lector. Estas no respondían de forma directa a las preferencias del usuario, su objetivo era, por el contrario, favorecer la serendipia ${ }^{11}$ informativa en la misma medida que estaba presente en los medios tradicionales. Es decir, cuando una persona compraba un periódico impreso, allí se encontraba con una amplia variedad de temas, muchos de ellos alejados de lo que, a priori, podría considerar de su interés. Cuando este tema imprevisto lograba despertar la fascinación oculta del lector y ampliar sus horizontes de consumo informativo, se generaba serendipia" (Suárez Villegas y Cruz Álvarez, 2012) ${ }^{12}$.

Los medios que podemos llamar ya 'históricos' han de valerse, pues, de sus propios entornos digitales y de las Redes sociales -que pretenden controlar, he ahí la dificultad- para poder ofrecer un grado de personalización competitivo y adaptarse a los nuevos formatos, allende el tradicional papel.

Nuestra inicial hipótesis de sobreimposición del nuevo modelo sobre el antiguo comunicativo se va corroborando dados los abrumadores datos hallados.

\subsubsection{Multimedialidad}

La innovadora forma de interacción de la Redes sociales, y en esto se asienta su radical importancia ante un consumidor audiovisual del siglo XXI, frente a los procedimientos de navegación precedentes y ante los nuevos formatos digitales -que convergen en un ambiente descentralizado y no jerárquico dirigido por los usuarioshacen que el uso de Internet haya adquirido nuevas dimensiones y objetivos. Renovarse o morir. Convenimos con lo que ya describiéramos en el artículo "La Nueva Narrativa en el Periodismo Binario"13 en el 2010:

"La narración digital permite una brecha con la forma narrativa que yuxtapone contenidos de los medios convencionales porque favorece la combinación de elementos de varios tipos: videos, audios, imágenes fijas o modelos 3-D. Mientras los medios convencionales trabajan de forma lineal, la lógica estructural en el mundo digital trabaja de forma modular y en constante evolución."

En este contexto, las producciones de prensa, radio y audiovisuales se convierten en gotas en el océano: son sólo otro medio más, por muy importantes recursos que los respalden, lo que hace la excepcionalidad del contenido mucho más necesaria si

\footnotetext{
${ }^{11}$ Serendipia (palabra hindi, a través del inglés) puede traducirse por chiripa o casualidad en español.

${ }^{12}$ Suárez Villegas, J. C. y Cruz Álvarez, J. (2012). Problemas éticos de la instantaneidad informativa en el entorno digital. Disponible en: http://dialnet.unirioja.es/descarga/articulo/4248038.pdf Consultado el 20 de agosto de 2013.

${ }^{13}$ González Oñate, C. y Caldevilla Domínguez, D. (2010). La Nueva Narrativa en el Periodismo Binario, en Sabés Turmo, F. y Verón Lassa, J. J. (coord.). El periodismo Digital desde la perspectiva de la investigación universitaria. Huesca: Ed. De la Asociación de la Prensa de Aragón. Disponible en: http://undecimo.congresoperiodismo.com/pdf/libro.pdf.
} 
cabe. En el mismo sentido, los apartados digitales de los viejos grupos, pueden aprovecharse de esta multimedialidad para obtener acceso a un verdadero tesoro de imágenes de recurso, obtenidas por testigos directos de los hechos narrados.

\subsubsection{Multiedición y retroalimentación}

Estas dos características definitorias de las Redes sociales, están ligadas a la primera enunciada: la interactividad. La tendencia actual marca que los contenidos no se conciban ya con el principio de "leer y olvidar" sino de "emitir y perdurar" lo que ha concitado nuevas realidades jurídicas derivadas del hecho social, como el derecho al olvido (Simón Castellano, 2014).

Según Lévy (2004) ${ }^{14}$, "la implantación de la narrativa de producción social está siendo facilitada por las tecnologías de la información y la comunicación, las cuales están permitiendo el fortalecimiento de una llamada "inteligencia colectiva" que suscita la acción conjunta para el intercambio de conocimientos y las tomas de decisión y, por qué no, para la elaboración de noticias.

Visto desde este punto de vista el leitmotiv de la Red 2.0 es el caldo de cultivo de la creación colectiva. Estas aplicaciones de "segunda generación", buscan someter la distancia entre los que acceden a la Web y los que publican en ella información."

Así Lévy apuntala nuestra impresión de que cualquier usuario en una red social o en la web/blog 2.0 puede constituirse en emisor, transmisor y receptor de información en un breve lapso de tiempo, casi simultáneo.

En un medio virtual la información puede ser analizada y estudiada por millones de usuarios al mismo tiempo, permitiendo que sea editada y complementada, para el provecho general. La actualización permanente de la información, en enciclopedias virtuales -como por ejemplo la Wikipedia (y todo el fenómeno Wiki)- permite la obtención de información muy completa y fiable, porque cientos de usuarios la juzgan y completan cada pocos minutos, pero también se impone un necesario contraste con otras fuentes y soportes: cualquiera puede editar una entrada, lo que supone un riesgo de segmentación de la información o pérdida de información objetiva amén de la posibilidad de una voluntad malintencionada, que tampoco debe ser nunca ignorada.

\section{Conflicto con el fenómeno "Media" anterior}

En los últimos años internet se ha convertido en algo más que un campo de atención suplementario para los creadores de contenido: ha pasado a ser un objetivo en sí misma: al diversificarse la atención de la audiencia y el empleo que esta hace del tiempo, también lo hacen los esfuerzos de los emisores de mensajes lo que, en última instancia, puede ser perjudicial para sectores de este último grupo, como

\footnotetext{
${ }^{14}$ Lévy, P. (2004). Inteligencia Colectiva. Por una antropología del ciberespacio. Recurso en línea. Ebook disponible en http://inteligenciacolectiva.bvsalud.org.Consultado el 20 de agosto de 2014.
} 
puede comprobarse en este gráfico que recoge la evolución de la inversión publicitaria en prensa escrita e internet en Estados Unidos:

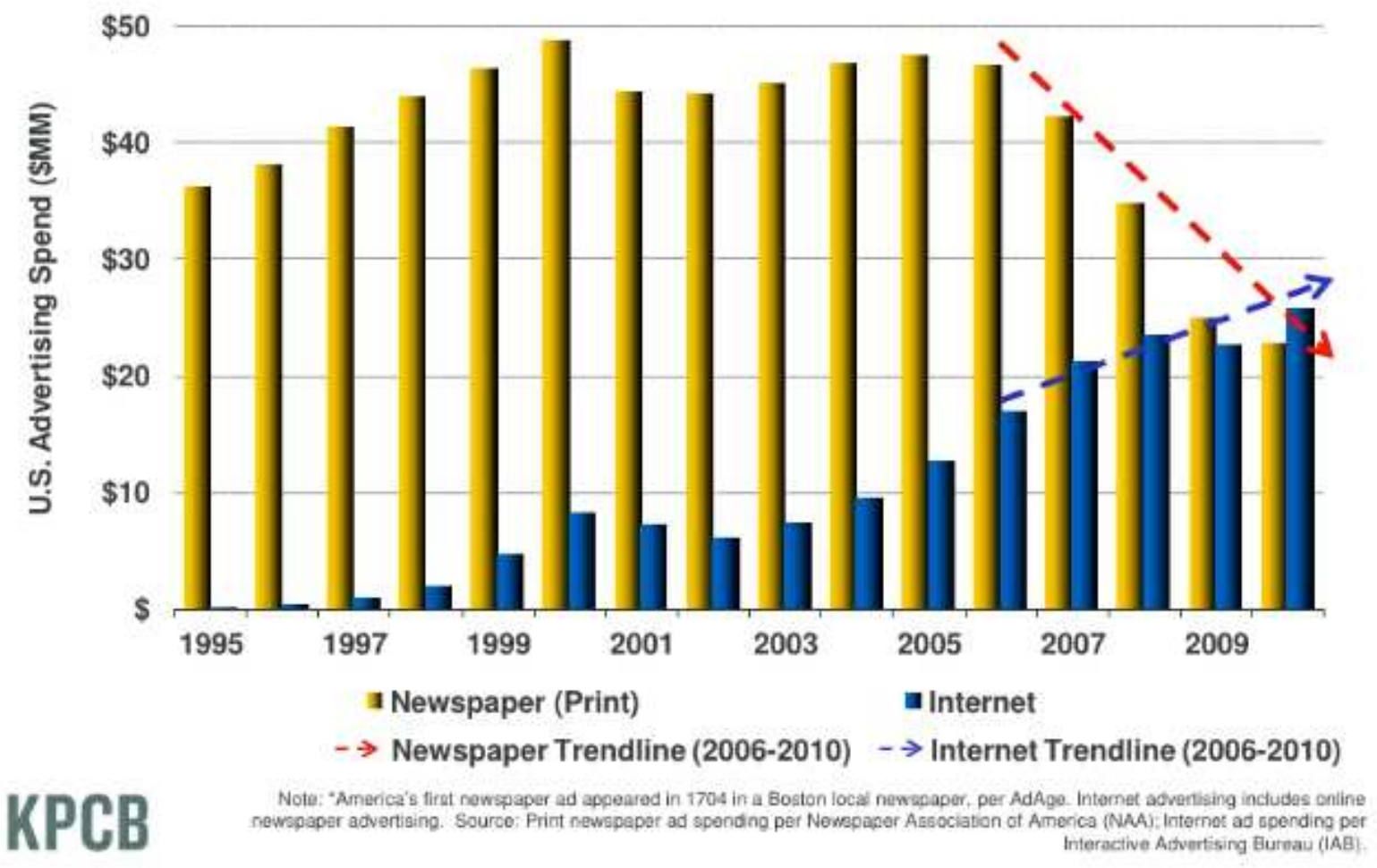

Imagen 2: Gasto publicitario en prensa frente a Internet en EE.UU. (1995-2010) Fuente: Kleiner Perkins Caufield Byers (www.slideshare.net/kleinerperkins/kpcbinternet-trends-2012)

Si bien una parte del descenso en las inversiones publicitarias es achacable a la crisis, una mirada a España nos indica así mismo no solo que el contexto imperante en los últimos años afecta también a los medios digitales, sino que son los medios tradicionales los que más acuciantemente lo sufren (INFOADEX 2013) ${ }^{15}$ con una diferencia notable en las caídas de inversión ( $8 \%$ frente a 0,5\% del entorno digital).

En el primer semestre de 2014, la tendencia es incluso más marcada. Siempre según Infoadex: 
Inversión publicitaria por medios en el primer semestre de 2014

\begin{tabular}{l|c|c|c}
\hline Medios convencionales & $1 S^{\prime} 13$ & $1 \mathbf{S}^{\prime} 14$ & $\%$ evol. \\
\hline Cine & 6,3 & 7,2 & 12,9 \\
\hline Diarios & 293,6 & 282,8 & $-3,7$ \\
\hline Dominicales & 18,8 & 16,8 & $-10,6$ \\
\hline Exterior $(*)(*)$ & 142,2 & 142,8 & 0,4 \\
\hline Internet $(*)$ & 171,3 & 179,4 & 4,7 \\
\hline Radio $\left(^{*}\right.$ & 166,7 & 171,8 & 3,1 \\
\hline Revistas & 135,2 & 131,2 & $-2,9$ \\
\hline Televisión & 884,4 & 935,0 & 5,7 \\
\hline TV's. Nacionales en abierto & 798,9 & 846,1 & 5,9 \\
\hline TV's Autonómicas & 62,3 & 60,0 & $-3,6$ \\
\hline Canales de pago & 23,2 & 28,9 & 24,3 \\
\hline Total medios convencionales & $1.818,5$ & $1.867,0$ & 2,7 \\
\hline
\end{tabular}

Fuente InfoAdex. Datos en millones de $\epsilon$

(7) Incluye exclusivamente los soportes y formatos controlados por infoAdex (para internet: los formatos gráficos) (*) Se ha actualizado la inversión de exterior de 2013 por aumento de cobertura

Imagen 3: Inversión publicitaria por medios en el primer trimestre de 2014.

Fuente: INFOADEX (www.infoadex.es/InfoAdex Resumen Est Inv 2013.pdf)

De este modo, la enajenación de las audiencias hacia el entorno digital 2.0 tendría un efecto colateral o adjunto en la redistribución de los ingresos por publicidad, principal fuente financiera del sector tradicional.

En la actualidad y según los resultados publicados por Crunchbase ${ }^{16}$ (base de datos con estadísticas relativas a empresas como las que analizamos aquí) podemos aproximarnos a la cantidad de usuarios de cada una de las redes: Facebook tiene 400 millones de usuarios frente a los 125 millones de usuarios que posee Myspace.

Basándonos en el estudio de las estadísticas de Facebook, por entender que ésta es la mayor red social, hemos considerado conveniente estudiar más a fondo qué tipo de usuario es el llamado 'usuario medio'. De las encuestas realizadas en Estados Unidos hasta 2013, resolvemos que el usuario medio es normalmente una chica de entre 25 y 34 años. (Para 2009 la media estaba entre 18 y 34, lo que indica un envejecimiento).

Todos estos datos numéricos no hacen sino complementar con cifras humanas las cifras de inversión, certificando la razón por la que se está produciendo un desvío de los recursos empresariales hacia el sector digital.

${ }^{16}$ Disponible en: www.crunchbase.com. Consultado el 20 de agosto de 2014. 


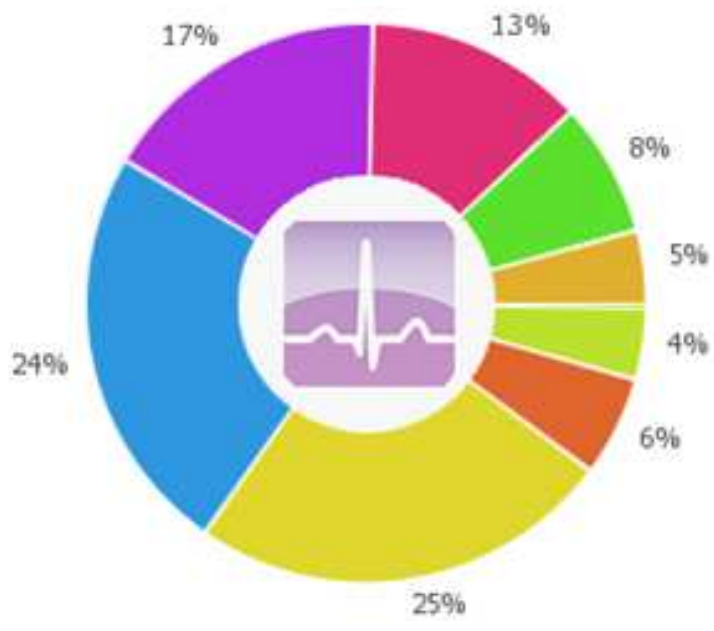

\begin{tabular}{|rr}
$13-15$ & $4 \%=$ \\
$16-17$ & $6 \%=$ \\
\hline $18-24$ & $25 \%=$ \\
\hline $25-34$ & $24 \%=$ \\
\hline $35-44$ & $17 \%=$ \\
\hline $45-54$ & $13 \%=$ \\
$55-64$ & $8 \%=$ \\
$65-0$ & $5 \%=$ \\
\hline
\end{tabular}

Imagen 4: Usuarios de Facebook por edades en EEUU.

Fuente: Facebook Stats (https://chrome.google.com/webstore/detail/facebookstats/kmkpokpaimeklljpdkakobjepcnpmhok)

El estudio que muestra la gráfica que sigue, fue realizado entre los años 2011 y 2014. Se pueden extraer conclusiones de carácter significativo como por ejemplo: la inclinación política, el nivel de estudios o los intereses de los usuarios norteamericanos de la red Facebook, incluso clasificados por estados. 


\section{Revista de Comunicación de la SEECI. (Noviembre 2014). Año XVII (35), 106-127 ISSN: 1576-3420}

\begin{tabular}{|c|c|c|c|c|c|}
\hline$\underline{1}$ & LASOF JA & UARY, 2011] & [AS OF JA & IUARY, 2014] & \\
\hline GENDER & USERS & PERCENTAGE & USERS & PERCENTAGE & GROWTH \\
\hline US Males & $63,645,480$ & $43.4 \%$ & $82,000,000$ & $45.6 \%$ & $28.8 \%$ \\
\hline Us Females & $80,711,340$ & $55.0 \%$ & $96,000,000$ & $53.3 \%$ & $18.9 \%$ \\
\hline Unknown & $2,448,180$ & $1.7 \%$ & $2,000,000$ & $1.1 \%$ & $-18 \cdot 3 \%$ \\
\hline Total US & $146,805,000$ & $100.0 \%$ & $180,000,000$ & $100.0 \%$ & $22.6 \%$ \\
\hline AGE & USERS & PERCENTAGE & USERS & PERCENTAGE & GRONTH \\
\hline $13-17$ & $13,114,780$ & $8.9 \%$ & $9,800,000$ & $5.4 \%$ & $-25.3 \%$ \\
\hline $18-24$ & $45,406,460$ & $30.9 \%$ & $42,000,000$ & $23.3 \%$ & $-7.5 \%$ \\
\hline $25-34$ & $33,171,080$ & $22.6 \%$ & $44,000,000$ & $24.4 \%$ & $32.6 \%$ \\
\hline $35-54$ & $39,595,900$ & $27.0 \%$ & $56,000,000$ & $31.1 \%$ & $41.4 \%$ \\
\hline $55+$ & $15,516,780$ & $10.6 \%$ & $28,000,000$ & $15.6 \%$ & $80.4 \%$ \\
\hline GEOGRAPHY & USERS & PERCENTAGE & USERS & PERCENTAGE & GROWTH \\
\hline New York & $4,369,820$ & $3.0 \%$ & $9,600,000$ & $5.3 \%$ & $119.7 \%$ \\
\hline Chicago & $3,007,720$ & $2.0 \%$ & $3,800,000$ & $2.1 \%$ & $26.3 \%$ \\
\hline Los Angeles & $2,931,480$ & $2.0 \%$ & $6,200,000$ & $3.4 \%$ & $111.5 \%$ \\
\hline Miami & $1,638,240$ & $1.1 \%$ & $2,400,000$ & $1.3 \%$ & $46.5 \%$ \\
\hline Houston & $2,262,600$ & $1.5 \%$ & $2,800,000$ & $1.6 \%$ & $23.8 \%$ \\
\hline Atlanta & $1,638,240$ & $1.1 \%$ & $2,400,000$ & $1.3 \%$ & $46.5 \%$ \\
\hline Washington DC & $1,682,460$ & $1.1 \%$ & $2,400,000$ & $1.3 \%$ & $42.6 \%$ \\
\hline Philadelphía & $1,564,940$ & $1.1 \%$ & $2,600,000$ & $1.4 \%$ & $66.1 \%$ \\
\hline Boston & $1,065,560$ & $0.7 \%$ & $2,000,000$ & $1.1 \%$ & $87.7 \%$ \\
\hline San Francisco & 740,040 & $0.5 \%$ & $1,840,000$ & $1.0 \%$ & $148.6 \%$ \\
\hline $\begin{array}{l}\text { CURRENT } \\
\text { ENROLLMENT }\end{array}$ & USERS & PERCENTAGE & USERS & PERCENTAGE & GROWTH \\
\hline High School & $7.292,080$ & $5.0 \%$ & $3,000,000$ & $1.7 \%$ & $-58.9 \%$ \\
\hline College & $11,748,840$ & $8.0 \%$ & $4,800,000$ & $2.7 \%$ & $-59.1 \%$ \\
\hline College Alumni & $36,441,600$ & $24.8 \%$ & $60,000,000$ & $33.3 \%$ & $64.6 \%$ \\
\hline INTERESTS & USERS & PERCENTAGE & USERS & PERCENTAGE & GROWTH \\
\hline Sex & $1,513,400$ & $1.0 \%$ & $5,000,000$ & $2.8 \%$ & $230.4 \%$ \\
\hline Drugs & 355,080 & $0.2 \%$ & 100,000 & $0.1 \%$ & $-71.8 \%$ \\
\hline Rock\&Roll (Music) & $1,915,180$ & $1.3 \%$ & $114,000,000$ & $63.3 \%$ & $5.852 .4 \%$ \\
\hline
\end{tabular}

Imagen 5: Clasificación por segmentos de los usuarios de Facebook Fuente: Facebook's Social Ads Platform con Istrategylabs ${ }^{17}$

Algunos datos estadísticos y económicos:

Más de 5 millones de dólares por minuto se gastan en Facebook cada día (en todo el mundo).

El usuario tiene como promedio 120 amigos en el sitio.

Más de 120 millones de usuarios inician sesión en Facebook al menos una vez al día. Más de 30 millones de usuarios actualizan sus datos al menos una vez al día. Más de mil millones de fotos subidas al sitio cada mes.

Más de mil millones de piezas de contenido (enlaces, noticias, blogs, notas, fotos, etc.) se comparten cada semana.

No obstante, convenimos que es necesario realizar un análisis de la situación en otra red que en España tiene una gran aceptación dirigida a jóvenes como es Tuenti. Sobre los datos estadísticos que ALEXA ${ }^{18}$ facilita, definiremos cuál es el llamado usuario medio de la red española y qué perfil lo define.

17 Istrategylabs. Disponible en: http://istrategylabs.com/2010/01/facebook-demographics-andstatistics-report-2010-145-growth-in-1-year/

${ }^{18}$ ALEXA: Disponible en: www.alexa.com/siteinfo/tuenti.com 


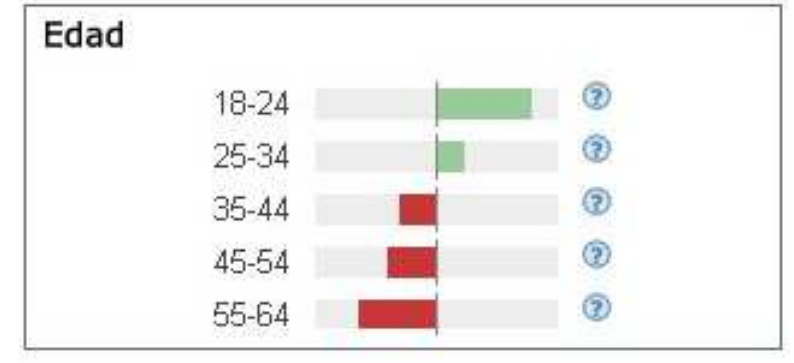

\section{Educación}

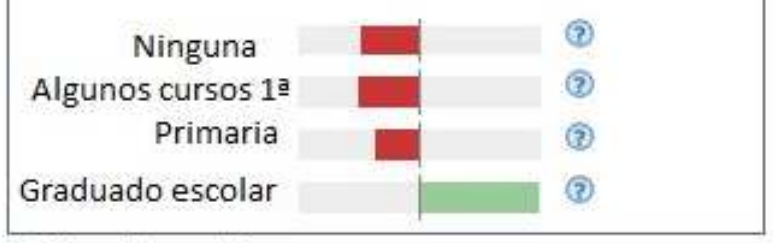

(c) Alexa Internet, Inc.

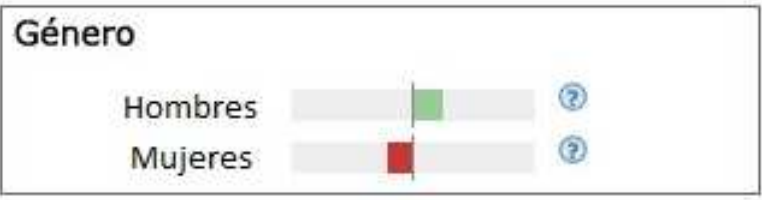

Con hijos
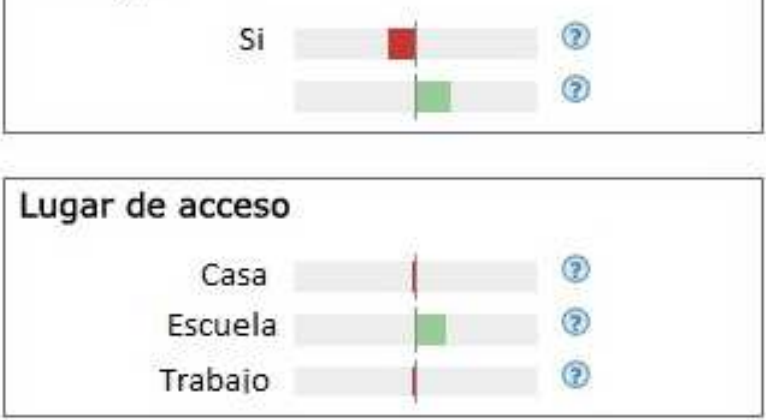

Tablas estadísticas de la audiencia media de la red social Tuenti a nivel mundial

Imagen 6: Audiencia media de Tuenti

Fuente: Alexa (www.alexa.com/siteinfo/tuenti.com)

Del análisis de las tablas colegimos que el usuario medio de la red social Tuenti es un varón de entre 18 y 24 años (posiblemente habrá usuarios de menor edad pero suelen mentir sobre la edad, en el momento de acceso, cuando son invitados a tener una nueva cuenta), sin hijos, con graduado escolar y que se suele conectar a la red desde la escuela, principalmente.

\subsection{Un pequeño DAFO sobre las Redes sociales y lo 2.0}

\subsubsection{Ventajas:}

- Están transformando las leyes de mercadotecnia y la publicidad

- Modifican las fórmulas de redacción y periodismo clásico permitiendo información de manera inmediata.

- Se pueden aunar intereses, trabajar colaborativamente y compartir información (Facilitan el trabajo incluso de los medios no digitales)

- Libertad semi-absoluta de contenidos: variedad ilimitada

- Han surgido grupos de cooperación y manifestaciones a nivel mundial. (Al margen de los canales de expresión previos.)

- Ofrecen posibilidades incontables para el Ocio, a la carta.

- Interactividad. Permite una retroalimentación informativa casi instantánea y con poco control. 


\subsubsection{Desventajas:}

- Dispersión de la atención. Ralentización de las conversaciones por la característica multitarea de las Redes sociales. Los usuarios pueden tener abierta la página en el navegador y estar haciendo más cosas a la vez o tener varias conversaciones simultáneas.

- Reducción de la productividad.

- Riesgo de suplantación de la identidad.

- Expropiación de material colgado por la falta de seguridad o de privacidad de los usuarios.

- Individualismo. Posible tendencia al aislacionismo real frente a la sociabilidad en la red.

- Adicción a las Redes sociales y búsqueda infinita de contactos: falta de contactos reales y duraderos.

- Laxitud del lenguaje. ¿Decadencia o evolución?

- Emergencia ante nuevos virus cuyo efecto paralizaría la actividad de múltiples usuarios.

- Socialización también de grupos y personas con intenciones delictivas, chantajistas, extorsionadoras o terroristas. Surgen nuevos delitos informáticos y nuevas formas de asociación.

\section{RESULTADOS}

Los medios tradicionales, al igual que las empresas que invierten en sus posibles publicitarios, se están adaptando a la nueva realidad con el acicate -o puede que más bien el impedimento- de la crisis. Si bien no alcanzan los niveles de interactividad que las iniciativas menudas de los nativos digitales si alcanzan, se han hecho grandes avances en el terreno de la Multimedialidad. En otras palabras: una parte de esa creciente inversión en marketing digital irá a parar a los grupos mediáticos tradicionales, así como una parte no insignificante del tráfico de visitas. Las Redes sociales se nutren en no pequeña medida de las webs de los medios a la hora de resaltar y hacer circular noticias para su comentario y análisis por parte de los usuarios, lo que, en último término, redunda en beneficio de ambas partes. Tampoco es despreciable la herramienta laboral en que el 2.0 se ha convertido para los Medios como empresas que son: Las reuniones hasta alta horas podrán realizarse a través de redes o portales de índole profesional adquiriendo nuevas perspectivas de negocio los portales que permitan personalizar redes como por ejemplo el caso de elgg ${ }^{19}$.

La posibilidad de emitir informaciones $y$, por otro canal, recibir un feedback activo de los lectores ha incentivado en las agencias de noticias y medios de toda especie, el buscar activamente la noticia, foto o titular que sea "Trending Topic" en las Redes

\footnotetext{
${ }^{19}$ Plataforma social personalizable. Disponible en: http://elgg.org/
} 
sociales. Un empeño que genera sus propios puestos de trabajo, redefiniendo y ampliando el rol del periodista.

El problema sigue siendo que la producción de noticias resulta significativamente más cara para agencias y medios que para los portales de Internet. Y esta es una realidad más compleja aún de atajar, en un contexto en el que los recortes de personal se han convertido en una necesidad financiera, y no en una imposición del sistema de libre competencia.

Es indudable que solo la estabilidad económica nos dirá como será el modelo definitivo de hibridación entre la comunicación digital y analógica, como es indudable que este tendrá que acabar por producirse. Cuanto más tiempo se demore la integración de ambas realidades comunicacionales, más traumática resultará esta para el sector, donde la necesidad de obtener unos ingresos que nadie parece saber bien donde obtener, resulta cada vez más problemática. Los datos dicen que esos ingresos se hallan en la digitalización y, por tanto, es allí a donde deben encaminarse los pasos de las grandes plataformas, que deberían tener la capacidad empresarial y financiera para reorientar sus tendencias profesionales y de negocio.

\section{NIHIL ÓBSTAT . IMPRIMÁTUR}

\section{REFERENCIAS:}

- Alemañy Martínez, C. (2009). Redes sociales: una nueva vía para el aprendizaje, en Cuadernos de Educación y Desarrollo no 1, vol 1. Disponible en: www.eumed.net/rev/ced/01/cam4.htm. Consultado el 30 de agosto de 2014.

- ALEXA: Página de estadísticas de Amazon.com. Disponible en:

- Alonso Mosquera, H. y Bartolomé Muñoz de Luna, Á. (2014). Redes sociales y consumidores: participación y construcción de imagen, en Revista Historia y Comunicación Social, Vol. 19, no especial de Febrero, p. 211-221. http://dx.doi.org/10.5209/rev HICS.2014.v19.45022.

- Álvarez, R. (2014). Edarling o Meetic: Comparativa. Disponible en: http://buscarparejaenlared.com/edarling-o-meetic-comparativa/.

- Bautista Sancho, L. (2013). Relatos 2.0: las autobiografías en la Web social; en Gonzálvez Valléz, J. E. (Coord.): Redes sociales y lo 2.0 y 3.0. Madrid: Visión Libros.

- Caldevilla Domínguez, D. (2009). La sociedad digital que crea redes, en Revista Icono 14, no 2. Disponible en: www.icono14.net/index.php/eventos/ici-sociedad-digital. Consultado el 28 de julio de 2014.

- Caldevilla Domínguez, D. (2010). El hombre binario, en Comunicación y hombre, $\mathrm{n}^{\circ}$ 6. Disponible en: www.redalyc.org/articulo.oa?id=129418690007.

- Caldevilla Domínguez, D. (2013). Efectos actuales de la "sobreinformación" y la "infoxicación" a través de la experiencia de las bitácoras y del proyecto I+D avanza 'Radiofriends', en Revista de Comunicación de la SEECI, no 30. 
Disponible en: www.seeci.net/revista/index.php/seeci/article/view/7/pdf 21. DOI: http://dx.doi.org/10.15198/seeci.2013.30.34-56

- Caldevilla Domínguez, D. y Visa Barbosa, M. (2013). El periodisme digital de proximitat. Història $\mathrm{i}$ usos actuals. Estudi de VilaWeb local $\mathrm{i}$ del portal Madridiario, en Revista Anàlisi, quaderns de comunicació i cultura, no 43, p. 29-42.

Disponible

en:

http://journals.uoc.edu/index.php/analisi/article/view/n49-caldevilla-

visa/pdf 23. Consultado el 18 de agosto de 2014.

- Campos Freire, F. (2008). Las redes sociales trastocan los modelos de los medios de comunicación tradicionales, en Revista Latina de Comunicación Social, no 63, p. 287-293. www.ull.es/publicaciones/latina/ 2008. Consultado el 28 de julio de 2014.

- Castelló Martínez, A. (2010). Estrategias empresariales en la Web 2.0. Las Redes sociales online. Alicante: Editorial ECU.

- Castells, M. (2008). La autocomunicación de Masas. Disponible en: www.renata.edu.co/index.php/component/content/article/5-noticias/191ieres-un-autista-digital-por-manuel-castells-.html. Consultado el 20 de agosto de 2014.

- Cornellá, A. (2000). Infonomia.com: la empresa es información. Bilbao: Deusto.

- Dawson, R. (2006). Artículo sobre sus trabajos. Disponible en: http://www.marketingdirecto.com/actualidad/medios/el-ultimo-periodicoespanol-en-papel-se-publicara-en-2024/ sobre el documento: http://futureexploration.net/Newspaper Extinction Timeline.pdf. Consultado el 18 de agosto de 2014.

- Del Moral, J. A. (2005). Redes sociales ¿Moda o nuevo paradigma?. Madrid: Asociación de usuarios de Internet.

- Doval Avendaño, M. y Martínez Rodríguez, B. (2012). La audiencia activa en twitter: análisis de la retirada de un artículo de opinión en el mundo, en Estudios sobre el mensaje periodístico, no 18. Disponible en: http://revistas.ucm.es/index.php/esmp/article/viewfile/39354/37901. DOI: http://dx.doi.org/10.5209/rev esmp.2012.v18.n1.39354. Consultado el 10 de agosto de 2014.

- FACEBOOK STATS (2014). Estadísticas oficiales de Facebook. Disponible en: https://chrome.google.com/webstore/detail/facebookstats/kmkpokpaimeklljpdkakobjepcnpmhok. Consultado el 28 de julio de 2014.

- Gómez-Escalonilla, G.: Géneros informativos en la redacción periodística hipertextual, en García Jiménez, A. y Rupérez, P. (2007). Aproximaciones al periodismo digital. Madrid: Dykinson.

- González Oñate, C. y Caldevilla Domínguez, D. (2010). La Nueva Narrativa en el Periodismo Binario, en Sabés Turmo, F. y Verón Lassa, J. J. (coord.). El periodismo Digital desde la perspectiva de la investigación universitaria. Huesca: Asociación de la Prensa de Aragón. Disponible en: http://undecimo.congresoperiodismo.com/pdf/libro.pdf. 
- INE: Informe sobre equipamiento y uso de TIC en los hogares. Disponible en: www.ine.es/jaxi/menu.do?type=pcaxis\&path=/t25/p450/a2010/\&file=pcaxis Consultada el 28 de julio de 2014.

- INFOADEX 2013 (2014). Informe anual 2013. Disponible en: www.infoadex.es/InfoAdex Resumen Est Inv 2013.pdf. Consultado el 20 de agosto de 2014.

- IREDES, (2013) Mapa de las Redes sociales. Disponible en: www.iredes.es/2013/03/tercera-version-del-mapa-iredes/ Consultada el 28 de julio de 2014.

- ISTRATEgYlABS (2014). Facebook Demografics. Disponible en: http://istrategylabs.com/2010/01/facebook-demographics-and-statisticsreport-2010-145-growth-in-1-year/ www.scribd.com/doc/17152718/Facebook-Demographics-Statistics-2009. Consultado el 20 de agosto de 2014.

- Kischinevsky, M. (2009). Cultura da portabilidade. Novos usos do rádio e sociabilidades em mídia Sonora, en OBS Journal, no 8, p. 223-238. Disponible en: http://obs.obercom.pt/index.php/obs/article/view/271/241. Consultado el 10 de agosto de 2014.

- KLEINER PERKINS CAUFIELD BYERS (2012). Informe sobre gasto publicitario. Disponible en: (www.slideshare.net/kleinerperkins/kpcb-internet-trends-2012). Consultado el 20 de agosto de 2014.

- Lévy, P. (2004). Inteligencia Colectiva. Por una antropología del ciberespacio. Disponible en: http://inteligenciacolectiva.bvsalud.org. Consultado el 20 de agosto de 2014.

- Martínez Molina, M. (2010). En un escenario complejo de transformación. La crisis de los grandes periódicos, en Infoamérica: Iberoamerican Communication Review, no 2, p. 139-148. Disponible en: http://dialnet.unirioja.es/servlet/articulo?codigo $=3918650$.

- McAfee, A. (2006). Enterprise 2.0: The Dawn of Emergent Collaboration, en MIT Sloan Management Review. Disponible en: http://adamkcarson.files. wordpress.com/2006/12/enterprise 20 the dawn of emergent collaboration by andrew mcafee.pdf. Consultado el 30 de Agosto de 2014.

- O'Reilly, T. (2004). "What is web 2.0". Conferencia. Disponible en http://oreilly.com/web2/archive/what-is-web-20.html Consultado 30 de Agosto de 2014.

- ONTSI (2013): Informe anual la Sociedad en red 2012. Disponible en www.ontsi.red.es/ontsi/es/estudios-informes. Consultado 30 de Agosto de 2014.

- Piñeiro-Otero, T. y Caldevilla Domínguez, D. (2011). Podcasting didáctico. Una aproximación a su uso en el ámbito de la universidad española, en Sapiens. Revista Universitaria de Investigación, no 2, diciembre. Disponible en: www2.scielo.org.ve/pdf/sp/v12n2/art02.pdf. Consultado el 18 de agosto de 2014. 
- Ponce, I. (2012). Historia de las Redes sociales. Disponible en http://recursostic.educacion.es/observatorio/web/ca/internet/web-20/1043redes-sociales?start $=2$. Consultado el 20 de agosto de 2014.

- Prensky, M. (2001). Digital Natives, digital inmigrants, en On the Horizont, vol. $9055 . \quad n^{\circ} \quad$ Disponible en: www.emeraldinsight.com/journals.htm?articleid=1532742 Consultado el 30 de Agosto de 2014.

- Rafaeli, S. (1988) Interactivity: From new media to communication, en Hawkins, R. P.; Wiemann, J. M. \& Pingree S. (Eds.), Sage Annual Review of Communication Research: Advancing Communication Science: Merging Mass and Interpersonal Processes, 16, 110-134. Beverly Hills: Sage. [en línea] Disponible en: http://gsb.haifa.ac.il/ sheizaf/interactivity/Consultado el 28 de julio de 2014.

- Rodríguez Andrés, R. y Ureña Uceda, D. (2011). Diez razones para el uso de Twitter como herramienta en la comunicación política y electoral, en Revista Comunicación y pluralismo, no 10 . Disponible en: http://dadun.unav.edu/bitstream/10171/35625/1/2011.\%20Twitter\%20y\%20Pol\%C3\%ADtica\%20\%28Comunicaci\%C3\%B3n\%20y\% 20Pluralismo\%29.pdf.

- Simón Castellano, P. (2014). Derecho al olvido y protección de datos. Disponible en: http://blog.peresimon.com/.

- Sorokin, P. A. (1947 y 1996). Sociedad, cultura y personalidad: Su estructura y su dinámica. Madrid:Aguilar.

- Suárez Villegas, J. C. y Cruz Álvarez, J. (2012). Problemas éticos de la instantaneidad informativa en el entorno digital. Disponible en: http://dialnet.unirioja.es/descarga/articulo/4248038.pdf Consultado el 20 de agosto de 2013.

- Tabernero, C.; Aranda, D. y Sánchez, J. (2010). Juventud y tecnologías digitales: espacios de ocio, participación y aprendizaje, en Revista de Estudios de Juventud, no 88, p. 77-96.

- Túñez, M. y Sixto, J. (2012). Las redes sociales como entorno docente: análisis del uso de Facebook en la docencia universitaria, en Pixel Bit Revista de medios y educación, no 41, p. 77-92. http://acdc.sav.us.es/pixelbit/images/stories/A11 011-V1 premaqpreprint.pdf. Consultado el 28 de julio de 2014.

\section{AUTOR: David Caldevilla Domínguez}

Prof. Dr. David Caldevilla Domínguez. Licenciado y Doctor en Ciencias de la Información, (Comunicación Audiovisual por la U. Complutense). Acreditado a titular (ANECA). Docente en: U. Complutense, U. Europea de Madrid, IED, ESERP e IPAM. Ponente y conferenciante en diversos cursos y profesor en varios títulos propios. Secretario General de la SEECI y del "Fórum Internacional de la Comunicación y Relaciones Públicas". Investigador Principal (IP) del Grupo Complutense de 
Investigación 'Conciliumt. Miembro de comités científicos en numerosos congresos y revistas científicas internacionales. Ponente en más de 70 congresos internacionales. Director de los Congresos CUICIID. Firma invitada en diversas publicaciones y Tertuliano radiofónico en COPE y RADIO INTERECONOMÍA. 'Medalla al mérito profesional' por la revista "Actualidad económica".

http://orcid.org/0000-0002-9850-1350

Researcher ID: D-7020-2014

[ G wVd-AnwAAAA]] 